\title{
THE INTRA-OCULAR PRESSURE AND DRAINAGE OF THE AQUEOUS HUMOUR
}

BY

FREDERICK RIDLEY

LON DON

(Received for publication December 11, 1930)

IN a recent article in this Journal, Duke-Elder has discussed my work upon this problem. As many of those addressed may not have read my paper, which was published in The British Journal of Experimental Pathology, 1930, attention may be drawn to some points not clearly set out by him.

In the second paragraph he refers to my introduction in which existing theories of aqueous drainage are discussed. I am aware that "the failure of particulate matter to pass through the endothelial cells of Schlemm's canal has no relation to the passage of fluid." This observation has no bearing upon the context of my paper. Speaking of Thomson's speculation, "that the lymph spaces around the angle may be provided with a system of valve-like openings," I quote the work of Nuel and Benoit (1895) who showed that the minute particles of indian ink do not pass into the canal of Schlemm from the anterior chamber, and conclude that such valve-like openings cannot exist. It is held that I have "failed to show that particulate matter is delivered out of the eye through the cornea." I did not attempt such a task.

Throughout the article I am rebuked for failing to recognise previous work. Where a previous worker has employed a similar technique and in all cases of quotation or reference, the reference is given. I have not given detailed references to the large number of workers upon familiar subjects.

My paper brings forward experimental evidence that the normal living cornea is permeable to diffusible substances and that the osmotic pressure due to the tear protein and the hydrostatic force exerted by the intra-ocular pressure determine the constant passage of fluid through the cornea.

Against these experiments, Duke-Elder "puts forward one only which is to his mind conclusive." An experiment in which methylene blue is introduced into the anterior chamber of a dog at a pressure not more than $2 \mathrm{~mm} . \mathrm{Hg}$ above the normal intra-ocular pressure is described. After one and a half minutes the blue appears in the episcleral veins. This experiment is held to prove conclusively that the cornea is not an available channel of exit since no blue is seen in the cornea or conjunctival sac in one and a half 
minutes. It is certain that the blue will not pass through the cornea in this time. No such claim has been made. Indeed a radicle so small as ammonium does not pass through in measurable amount in less than 15 minutes. As a refutation of my work, this experiment is irrelevant.

For a critical examination of experiments of this kind, reference may be made to Duke-Elder, 1927, $a$. where the conclusion is reached that such experiments may "prove anything or nothing," and to Duke-Elder, 1929, $a$. The experiment is nevertheless held to prove that the blue has passed into the episcleral veins via Schlemm's canal. It does not do so, all it proves is that if the experiment is performed blue will appear in the episcleral veins in one-and-a-half minutes.

Duke-Elder has shown by direct measurement in the dog that "The pressure in the exit veins is normally a little higher than the chamber pressure" and that "On raising the chamber pressure to a considerable height the pressure in the veins was found to rise coincidently" (Duke-Elder, 1929, b). Not until a chamber pressure of $40 \mathrm{~mm} . \mathrm{Hg}$ is reached does the exit vein pressure fall to $39 \mathrm{~mm} . \mathrm{Hg}$ by comparison. Since the chamber pressure in this experiment is raised not more than $2 \mathrm{~mm} . \mathrm{Hg}$ the exit vein pressure is not less than the intra-ocular pressure. We must conclude that under the experimental conditions laid down fluid cannot pass into the episcleral veins via Schlemm's canal.

But it is stated that the blue appears in the episcleral veins in one-and-a-half minutes. The explanation is probably to be found in the fact that, "In the lower mammals, e.g., the dog, the venous anastomoses are large and most of the blood from the eye is returned to the extracranial venous system, while in man it normally flows into the intracranial system" (Parsons, 1904). In the dog there is a free anastomosis between the circle of Hovius and the vortex veins themselves (Duke-Elder, 1929, c.) The venous arrangements in the eye of the dog are such that blue will appear in the episcleral veins whatever may be its site of entry into the venous system. "As far as they have been investigated (methylene blue has been discussed) all substances seem to enter and leave the eye by a process of simple diffusion" (Duke-Elder, 1929, d.) The blue which appears in the episcleral veins might have entered the vascular system in the eye of the dog by diffusion into $(a)$ The canal of Schlemm; (b) The whole area of the capillaries of the ciliary body and iris. In the latter case the dye, having passed by diffusion into the capillaries, will be carried by the blood stream to the site at which it is observed. In the case of Schlemm's canal not only is the diffusion area minute by comparison but we have seen that there is no fluid stream to carry the blue. There can be little doubt that 
in this experiment the blue has passed into the episcleral veins via the capillaries of the ciliary body and iris. The experiment is not a refutation of my work since it has no bearing upon it, and what Duke-Elder, in his article, describes as obvious is at variance with his own experimental work and teaching and, to say the least, highly improbable.

I do not deny that a swelling of the vitreous may occur under experimental conditions of abnormal $\mathrm{pH}$ or salt concentration. $\mathrm{My}$ paper states that "there is no evidence that the variations in these factors necessary to cause such a volume change in the vitreous (of a living intact animal) occur." Duke-Elder supports this strongly. "The $\mathrm{pH}$ of the blood is a factor of extreme constancy." "Any treatment which will change the reaction of the blood to any marked extent upsets so extensively the essential functions of the experimental animals employed that observations of the intra-ocular pressure in these circumstances are of little value." (Trans. Ophthal. Soc. U.K., 1929, p. 102.)

Also Adams and Kerridge (1930) have shown that the $\mathrm{pH}$ of the vitreous in rabbits fed on naphthalene, in which extreme vitreous degeneration may occur, is remarkably constant. Similarly, I do not know of any evidence that the salt content of the blood in man falls, either in health or disease, sufficiently to cause a significant swelling of the vitreous at normal $\mathrm{pH}$. In "The nature of the vitreous body" (Duke-Elder, 1930); we read on page 49 that if the vitreous swells it does so by absorption of aqueous humour. It is important to observe that swelling of the vitreous can never produce an increase of volume of globe contents so long as any aqueous remains. If the vitreous swells the volume of aqueous plus vitreous decreases (Lewis, W.C., 1919) so that the volume of globe contents would be diminished by swelling of the vitreous and the intra-ocular pressure would fall; shrinking of the vitreous, on the other hand, might give rise to an increased intra-ocular pressure if the rate of shrinking were so rapid that fluid could not pass out of the eye into the capillaries sufficiently rapidly to compensate the small increase of volume of aqueous plus vitreous. In his article, and in many instances in his writing, my critic suggests that the passage of diffusible substances through a permeable membrane need bear no relation to the passage of fluid. It does bear this constant relation, that, where diffusible substances in water solution can pass through a membrane, water must do so if the hydrostatic and osmotic forces on either side of the membrane are not balanced. My paper states in a series of six equations the equilibria, both osmotic and hydrostatic, that must exist in the eye if fluid is not to enter or leave the capillaries of the uvea, for the intra-ocular pressure existing at the time of observation. The fact that membranes permeable to 
diffusible substances in solution in water are permeable to water itself is essential to an understanding of the problem under consideration.

The observation that hypotension may occur with maximal vasodilatation is familar in the experiment of opening the anterior chamber. Duke-Elder's reference is vague (Duke-Elder, 1926-29). In the experiment in which 30 per cent. saline solution is injected into an experimental animal the eye is subjected to an active dehydration and it is reasonable to suppose that vaso-dilatation is unable to counteract this decrease of volume of globe contents, as in the simpler experiment described above.

Duke-Elder says "section of an eye with chronically raised tension frequently shows a thin and atrophied choroid, ciliary body and iris, the whole uveal tract being obviously pressed almost out of existence by something else-the vitreous." Fuchs attributes this condition to "the atrophy which, after the subsidence of the early congestive symptoms, sets in in all parts of the uvea," and proceeds to describe the pathological changes, including fibrosis and vascular changes, which lead up to this end result. These changes cannot be described as a simple pressure atrophy.

The last paragraph in the criticism confuses the issue. Many workers have advanced evidence as to the composition, osmotic pressure, conductivity and other properties of the aqueous humour as compared with the blood plasma which suggests strongly that the aqueous is formed by a process of dialysation from the blood. My paper draws attention to the fact that such a procsss may be either "static dialysation," if the aqueous is stagnant, or "pressure dialysation" if the aqueous is subjected to a constant drainage, e.g., through the cornea. When we come to consider the possibility of applying Donnan's theory of membrane equilibria to this problem we have to remember, inter alia, the following reservations-

1. That Donnan's simple formula is not applicable to a system in which a protein containing fluid such as plasma, is separated from a protein free fluid such as aqueous, without suitable correction.

2. That it cannot be applied unless the assumption is made that the aqueous is stagnant.

Duke-Elder has attacked this problem by :--1. A full analysis of horse aqueous and serum. From these figures he claims to have demonstrated the following

a. That there is an unequal partitioning of the anions and cations between the aqueous and the blood plasma.

b. That this unequal partitioning is in accordance with Donnan's theory. 
c. That when the percentages of sodium and chlorine in particular are converted into concentration terms and the figures substituted in Donnan's simple formula :-(DukeElder, 1927, $b$.

$$
\begin{aligned}
& \text { viz. }[\mathrm{Na}] \times[\mathrm{Cl} .]=[\mathrm{Na}] \times[\mathrm{Cl} .] \\
& \text { aq. aq. blood blood } \\
& \text {, } 121 \times 123=145 \times 103 \\
& 148.83=149.35
\end{aligned}
$$

the apparent discrepancy of 0.3 per cent. can reasonably be explained-" as being within biological limits-"It is unjustifiable to hope for results of any more approximate accuracy." Considering these results in conjunction with the fact that the relationship holds good only for fluids which are stagnant, he concludes that "the aqueous is without an active circulation in the generally accepted sense of the term but rather it is essentially stagnant" (Duke-Elder, 1927, c).

2. Subsequent micro-analyses of sugar and chloride in aqueous and arterial and venous blood taken from the same animal at the same time are put forward in support of the figures and conclusions obtained from the major analysis. These micro-analyses only strengthen the main argument, however. They are incapable, alone, of supporting the belief that a Donnan equilibrium exists, for they do not supply information with regard to a pair of anions and cations such as sodium and chlorine. He returns to the figures derived from his major analysis when discussing the significance of those obtained in his micro-analyses. (Duke-Elder, 1927 d.)

My paper claims to prove that there is a constant drainage of fluid out of the anterior chamber through the cornea in the normal living eye. If this is so it is clear that the aqueous is not stagnant. DukeElder's work and mine are thus opposed.

Notwithstanding his complaint that this major analysis is "only a rough estimation" it remains the only evidence he has advanced which properly supports his claim to have demonstrated a Donnan equilibrium between the aqueous and the blood. This, in conjunction with the fact that the percentages of all the more important constituents are given to the fourth decimal place and that a paragraph is devoted to explain a discrepancy of 0.3 per cent. as being within the limits of biological error, appears to justify the careful consideration given in my paper to this analysis and the conclusions based upon it. This major analysis is open to the following criticism : 
1. It involves the comparison of a pooled sample of horse aqueous with a single sample (not similarly pooled) of horse serum. The composition of blood varies within wide limits; thus for man the normal chlorine content varies from 340 to $380 \mathrm{mgs}$. per 100 c.c. (blood plasma), sodium 325 to 350 mgs. per 100 c.c., sugar 60 to 180 mgs. per 100 c.c. It is reasonable to suppose that variations of a similar order of magnitude occur in the horse. The figures given by a single blood analysis may therefore involve quite large errors.

2. The comparison is made between aqueous and serum but the fluids it is attempted to compare are aqueous and capillary blood plasma. The following discrepancies are inherent.

(a) Capillary blood approximates to arterial rather than to venous blood. In passing from the arterial to the venous state a chloride shift occurs so that the chlorine content of venous plasma expressed as $\mathrm{NaCl}$ may be $342 \mathrm{mgs}$. per 100 c.c. as compared with 349 for arterial plasma; the serum is derived from venous blood and an error occurs in the chlorine estimation for this reason. It is to be noted that the sodium content of the plasma is not affected by the chloride shift. A greater discrepancy arises from the fact that "when blood is shed a chloride shift occurs from corpuscles to plasma, in vitro, unless escape of blood gases is prevented." (Harrison, 1930. Chemical Methods in Clinical Medicine, p. 173. The foregoing figures are derived from the blood analysis given on p. 305). In addition to these objections there is the fact that if a Donnan equilibrium exists between the aqueous and the blood then, substituting concentration terms in Donnan's simple formula (supra) the product $[\mathrm{Na}] \times[\mathrm{Cl}$.$] for the blood should exceed that for the$ aqueous by about 4 per cent. They should not be equal as DukeElder found them to be. For these reasons the writer does not accept the conclusion that there is normally no drainage of the aqueous.

With regard to the estimation of the osmotic pressure difference between blood and aqueous in which he obtained figures agreeing closely with those given by other workers using various methods I have preferred the work of Dieter (1925) because his investigation was well controlled and he used the depression of freezing-point technique. In this experiment the control is open to the criticism that the estimations of the conductivity and glucose-content of the aqueous show significant variations in the course of the experiment in many instances. The refractive index of the aqueous before and after the experiment was found to be the same to the sixth decimal place in six instances, but it is to be remembered that the Dipping refractometer employed has an instrumental error of \pm 3.7 at the fifth decimal place. (Duke-Elder, $1927 e$. and $1930 a$ a.) With regard 
to the method many workers consider that the depression of freezingpoint technique is preferable.

Duke-Elder states that my criticism of the application of the simple formulae of Donnan challenges an enormous amount of work done by physiologists and biochemists for the last two decades. I have referred this matter to Mr. G. S. Adair who states that "in the form given in my paper the criticism of Donnan's equation is in agreement with the most recent work on membrane equilibria, which shows that there are considerable deviations from the simple formulae of Donnan. Reference may be made to the papers by Van Slyke, Hastings, Murray and Sendroy (Jl. Biol.Chem., Vol.CXX, p. 701, 1925), and by Adair (Proc. Roy. Soc. A., Vol. CXX, p. 572, 1928), which show deviations of the order of magnitude referred to by Ridley."

\section{REFERENCES}

Adams and Kerridge.-Brit.Jl. of Ophthal., Vol. XIV, p. 397. 1930.

Dieter, W.-Arch. f. Augenheilk., pp. 96, 179. 1925.

Duke-Elder, W. S -The Nature of the Intra-ocular Fluids, pp. a. 81, 82, 83 : b. 69,$70 ;$ c. $77 ; d .31 ;$ e. $34 ; f .72 ;$ g. 54.1927.

- Recent Advances in Ophthalmology, pp. a. 176, 177; b. 181 ; c. 179 ; d. 201. 1929.

The Nature of the Vitreous Body, a, p. 40. 1930.

Fuchs.-Text Book of Ophthalmology. Eighth edition.

Lewis, W. C.-A System of Physical Chemistry, p. 356. 1919.

Nuel and Benoit.-Arch. d'Ophtal., p. 41. 1895.

Parsons, J. H.-The Pathology of the Eye. London. 1904.

\section{ABSTRACTS}

\section{I.-REFRACTION AND OPTICS}

(I) Ferree, C. E. and Rand, Gertrude (Baltimore).-Intensity of illumination and other factors influencing the sensitivity of the radial test for astigmatism. Amer. Jl. of Ophthal., October, 1929.

(1) Ferree and Rand find that the sensitivity of radial charts for detecting astigmatism can be much increased by raising the intensity of their illumination. The illumination should, if possible, be limited to the area of the chart, the surroundings being in subdued light. This can be done in one of two ways-the chart may be an opaque one, illuminated in front by a projecting lantern 